\title{
La cara és el mirall del cor: la fisiognomonia medieval i la literatura Antònia Carré
}

\begin{abstract}
En el capítol 813 del Dotzè del Crestià, Francesc Eiximenis diu: «la cara és mirall del cor, e qui sap bé jutjar la cara, per via de natura sap bé conèxer l'om aquell a què és naturalment inclinat» (Wittlin 1986-87: II, 316). Si el menoret pot fer una afirmació d'aquest tipus, que encara avui recull la llengua popular amb variants i que trobem en títols que estudien la matèria (Caro Baroja 1995, Porter 2005), és perquè havia adquirit els coneixements bàsics de fisiognomonia a través de la lectura de diversos manuals. Eiximenis parla del cor perquè segons la filosofia natural aristotèlica, que fonamenta la medicina medieval, en el cor resideix la calor vital, imprescindible per a la vida de l'organisme, i és l'òrgan responsable de la vida física i psíquica dels individus. Així, és el cor qui modula els comportaments afectius i els estats emocionals, qui governa les passions i els costums humans. En aquestes pàgines em proposo d'exposar breument què és la fisiognomonia, quins són els seus orígens, com era tractada a la baixa Edat Mitjana i com es divulga arreu, amb exemples extrets d'Eiximenis, de la crònica de Desclot i el Tirant lo Blanc.
\end{abstract}

\section{La fisiognomonia}

Des dels seus orígens grecs i passant per la tradició àrab, la fisiognomonia presenta dues formes de mirar-se els individus, l'una més experimental, l'altra més científica. Així, d'una banda hi ha la fisionomia, la visió simbòlica del cos, la intuïció de l'essència de les persones a partir de l'observació de trets físics concrets, que possibilita prediccions de futur. I de l'altra hi ha la fisiognomonia, la ciència que indaga en les lleis naturals del cos establertes a partir d'una sistematització doctrinal, lògica i epistemològica de les dades obtingudes mitjançant l'observació. Ambdues disciplines conviuen en el temps, es barregen, se solapen $i$ els autors utilitzen tant el terme d'arrel grega (fisiognomonia) com el d'arrel llatina (fisionomia) per referir-s'hi.

Des de la Grècia clàssica, metges i filòsofs (com Aristòtil, Hipòcrates i Galè) intenten contrarestar el component de creença de la disciplina, que la vinculava a la màntica, dotant-la de rigor científic i d'un mètode racional, alhora que excloïen de les seves argumentacions les causes sobrenaturals. Però malgrat aquests esforços, el lligam amb les arts endevinatòries no desapareix, com ho prova l'existència a Roma de metoposcopi, això és, de persones que prediuen el futur mirant el front o el rostre d'un individu, que tenim documentades per autors com Plini o Suetoni.

A la baixa Edat Mitjana, gràcies a la intervenció decidida d'uns quants filòsofs naturals -com Michael Scot, Albert el Gran, Roger Bacon i Pietro d'Abano- la fisiognomonia assolirà la categoria de scientia, de manera que es farà un lloc autònom en el pensament escolàstic, desvinculant-se del discurs religiós i també de l'àmbit de l'experimentum, limítrof amb l'endevinació i la màgia. L'etimologia atorgada al terme per Pietro d'Abano, el famós metge de Pàdua contemporani d'Arnau de Vilanova i considerat un dels homes més savis del seu temps, és en aquest sentit prou rellevant. En el seu Liber compilationis physionomie (1295) indica que phisionomia prové de phisis 'natura' i nomos 'llei', com diuen els grecs, no pas de phisis 'natura' i onoma 'nom' com volen alguns (Agrimi 2002:30). Ara bé, l'endevinació tampoc no desapareixerà de la disciplina, com ho demos- 
tra el compendi de fisiognomonia que va elaborar a partir de 1498 el metge i cirurgià bolonyès Bartolomeo della Rocca Coclès (Ziegler 2004), on fa una sèrie de prediccions sobre l'esperança de vida de personalitats rellevants del seu temps, com el papa Alexandre VI o el rei Carles VIII de França, que evidencien l'antipatia per la família valenciana o els sentiments antifrancesos de l'autor. El papa Borja, diu Coclès, té a la cara un dels signes que són senyal inequívoc de frau i engany, com és la vermellor, quasi púrpura, del nas i de

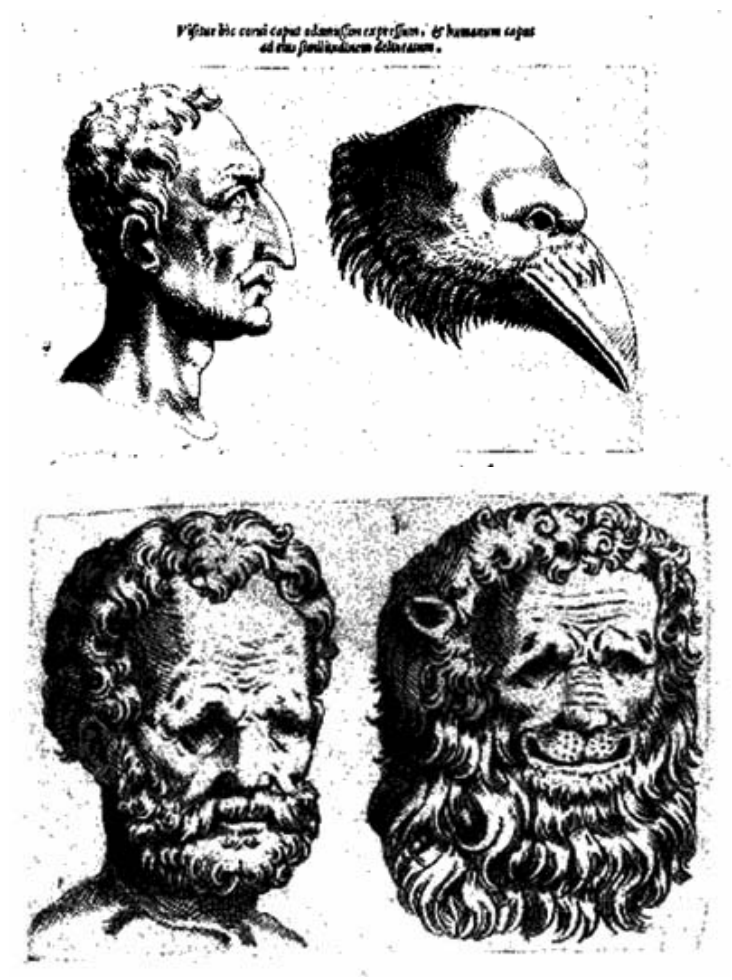

De humana physiognomia, de Giovanni Battista della Porta (1586). La imatge mostra l'aplicació del mètode zoològic. L'home amb aspecte de lleó i el front ben ample indica mediocritat d'intelligència.

les galtes. El tractat Chiromantie ac physionomie anastasis de Coclès ens serveix per apuntar tres coses. La primera és la importància que tenien totes aquestes teories en l'imaginari social i polític del moment, ja que Coclès va morir assassinat pocs mesos després de la publicació del llibre, el 1504, possiblement a instàncies d'algun dels personatges que no hi quedaven gaire bé. La segona és la medicalització de la fisiognomonia, ja que els signes són analitzats a partir de teories mè- diques. Per exemple, la vermellor de la pell del papa Alexandre VI és el resultat d'un excés de combustió interna de l'esperit animal, que engendra una tendència a la traïdoria, a la luxúria, a la violència i a la crueltat, afirma Coclès. I la tercera és la claredat amb què l'autor exposa com s'ha de practicar l'examen fisiognomònic.

\section{L'examen fisiognomònic}

Segons Coclès, s'ha de fer de tot el cos i despullat (pràctica habitual a l'hora de comprar un esclau o un criat o d'adoptar una criatura). Si això no és possible, l'anàlisi es pot fer de les espatlles cap amunt, passant després a d'altres òrgans del cos. Es comença amb un examen del color, la quantitat i la forma dels cabells, després s'estudien el front i els ulls, que són indicatius, tant l'un com els altres, de la capacitat intellectual. Tot seguit s'han de controlar els signes que hi ha a les mans, al pit, a les espatlles, a les cames, als peus, al ventre i a les natges, per aquest ordre i tenint en compte sempre que no s'han d'extreure mai conclusions d'un sol signe. L'observació de les línies de les mans és fonamental -la quiromància va esdevenir una part de la fisiognomonia- i ha d'anar precedida d'un rentat minuciós amb aigua tèbia. S'ha d'observar la mà dreta dels homes i l'esquerra de les dones i s'ha d'evitar l'observació de la mà d'una persona agitada per una emoció (com la ira), perquè provoca alteracions en el color natural de les línies. També convé observar com es mou tot el cos i analitzar la parla, ja que la manera d'expressarse és significativa del caràcter de les persones, i és per això que tots els tractats de fisiognomonia inclouen un capítol dedicat a la veu (Ziegler 2004: \$9-10).

La fisiognomonia medieval és una disciplina polimorfa. Albert el Gran l'homologa amb l'anatomia, Pere Hispà amb la fisiologia, Pietro d'Abano amb la medicina i l'astrologia, Guillem Hispà - que sembla que s'ha d'identificar amb Guillem d'Aragó, mestre en medicina a la Universitat de Montpeller cap al 1300 i autor de comentaris a textos mèdics (Val Naval 2006) - la situa en l'àmbit de la filosofia natural i la relaciona amb 
l'astrologia i la medicina, però també amb l'ètica, l'economia i la política, seguint així les petjades del Secretum secretorum, de Michael Scot, de Roger Bacon i de Pietro d'Abano (Agrimi 2002). La fisiognomonia és, doncs, una ciència natural i una ciència moral alhora.

\section{Pinzellades sobre els orígens grecs i llatins}

En els orígens clàssics de la fisiognomonia s'observa una clara utilitat pràctica de la disciplina. Els primers exemples de caracterització fisiognòmica que tenim documentats apareixen en els poemes homèrics, com ara la descripció del guerrer aqueu Tersites que podem Ilegir al cant II de la llíada. Un home amb els trets físics contraris a la bellesa dels herois -és guenyo, coix, geperut, amb poc cabell i encara de punta-, no pot ser un receptacle de virtuts. Així doncs, Tersites és un soldat vulgar, grollerot, insolent i curt d'enginy que rep el tracte que es mereix: una vegada que va acusar de cobdiciós Agamèmnon i de covard Aquilles, Ulisses el va assotar al davant de tothom per castigar-lo. I, ja en l'època clàssica, sabem que Pitàgores reclutava els joves que volien seguir els seus ensenyaments amb un examen del rostre i del cos, que el Fedó de Plató proposa establir la similitud entre l'home i els animals, tan típica dels tractats fisiognomònics i que Aristòtil accepta la idea que els trets físics poden aportar indicacions sobre els psíquics en el De animalibus.

El tractat més antic conservat sobre la matèria, de més ambició teòrica i que té com a objectiu fonamentar racionalment una ciència de naturalesa empírica i allunyar-la així de la màntica és la Physiognomonika, atribuïda a Aristòtil (Martínez \& Calvo 1999). Va circular sota l'autoria d'Aristòtil perquè les seves línies de pensament són peripatètiques: estableix una relació entre els fenòmens físics i els anímics, usa l'analogia homeanimal, que serà molt productiva en la disciplina, fixa la teoria de l'excellència del terme mitjà, expressada a l'Ètica a Nicòmac, i estipula l'oposició metodològica entre allò masculí i allò femení. Més tard, en l'època hellenística -i a partir de la parallela explicitació hipocràtica de la relació existent entre l'aspecte físic, l'estat de salut i el caràcter d'un individu a les Epidèmies (II, 5,1 i II,6,1)-, la Physiognomonika pseudoaristotèlica va ajudar a sistematitzar tipològicament les màscares usades en el teatre còmic de Menandre i va orientar els actors sobre la manera d'actuar i de gesticular (Martínez \& Calvo 1999: 32). Sota la falsa autoria d'Aristòtil va circular també un conjunt de textos escrit en la forma de preguntes i respostes que tenen relació amb la fisiognomonia. Són els Problemata Aristotelis, sorgits de l'escola peripatètica i que van anar-se ampliant fins al segle $\mathrm{V}$ o VI dC (Louis 1991-94).

\section{Mètodes fisiognomònics}

L'analogia entre home i animal estableix les pautes del mètode zoològic: com que cada espècie animal té un aspecte i un caràcter concrets, I'home que s'assembli físicament a un animal s'hi assemblarà per força anímicament. Els altres dos mètodes d'anàlisi de la fisiognomonia grega són l'etnològic -el terme de comparació són els pobles o les races- i l'etiològic, que dedueix els trets del caràcter a partir de l'expressió puntual de les emocions corresponents (Martínez \& Calvo 1999: 19-20).

La fisiognomonia gaudeix de considerable interès teòric en època romana. Galè la considera una auxiliar important de la medicina en el tractat Quod animi mores corporis temperamenta sequantur (García Ballester 1972). Polemó, que va comptar amb la protecció i l'amistat de l'emperador Adrià, va escriure un tractat de fisiognomonia d'arrel pseudoaristotèlica, que va ser seguit en el De physiognomonia liber, text anònim del segle IV dC (Martínez\& Calvo 1999: 24-25). Els coneixements fisiognomònics són utilitzats per disciplines diverses, com l'escultura, la historiografia o la literatura. Gràcies a Plutarc sabem que Alexandre el Gran només es deixava retratar per l'escultor Lisip perquè era qui més bé reflectia en bronze la seva energia:

La forma del cos d'Alexandre, les estàtues que millor la representen són les de Lisip, l'únic a qui ell mateix 
creia digne de modelar-lo. En efecte, allò que molts dels seus successors $i$ dels seus amics més tard imitaven, com era la tensió del coll lleugerament inclinat a l'esquerra, i aquella humitat dels seus ulls, l'artista les ha conservades d'una manera perfecta. (IV,1-2, Riba 1942: 6-8)

Suetoni va treure profit dels tractats del pseudo Aristòtil i de Polemó i ja fa molts anys es va demostrar que és el primer historiador que va introduir en la biografia dels seus dotze cèsars el retrat físic de costat amb un estudi moral del personatge (Couissin1953). En les Tusculanes, Ciceró argumenta que les característiques físiques d'un individu en condicionen les tendències i les passions, però que una voluntat ferma, una tria moral, pot modificar aquestes qualitats innates. Ho deixa ben clar amb l'exemple de Sòcrates:

\begin{abstract}
Aquells dels quals es diu que són de natural iracunds o compassius o envejosos, o alguna altra cosa de semblant, tenen, per dir-ho així, una complexió espiritual malaltissa, però es poden guarir, com es diu de Sòcrates. En una reunió, Zopir, que feia professió de conèixer el natural de cadascú basant-se en els seus trets fisiognòmics, li atribuí una multitud de vicis; els altres, que no havien observat en Sòcrates cap d'aquells vicis, esclafiren a riure, però Sòcrates mateix sortí en defensa de Zopir, dient que aquells vicis eren innats en ell, però que se n'havia desfet gràcies a la raó. (IV,37,80, Valentí1948-50: II, 97)
\end{abstract}

\section{La tradició àrab i la seva difusió}

A banda d'algunes referències a la fisiognomonia que hi ha al Qānūn fi-l-tibb (Canon medicine) d'Avicenna, un dels manuals bàsics per a la instrucció dels metges medievals, els dos textos àrabs fonamentals per a la disciplina són el Kitāb al-Mansurī fi-l-tibb (Liber ad Almansorem) de Rasís i el Kitāb Sirr al-Asrār, que en la tradició llatina va circular amb el nom de Secretum secretorum. Les versions llatines de totes aquestes obres estan vinculades a l'escola de traductors de Toledo, encara que la darrera també va penetrar a l'Europa llatina, en una altra versió, més àmplia, a partir de la cort siciliana.
L'apartat de fisiognomonia del Kitāb al-Mansurī de Rasís (filòsof i metge persa que va viure entre els segles IX i X) ocupa el segon tractat del llibre, que es va transmetre de manera autònoma des de finals del segle XII. El Kitāb al-Mansurī va ser conegut a Occident a partir de la traducció llatina que en fa ver Gerard de Cremona a Toledo al segle XII. L'apartat fisiognòmic d'aquesta obra va circular en dues versions. En una d'elles, destinada a la formació dels metges, s'integra en el text complet, és a dir, en els deu llibres dedicats a l'anatomia (I), a les complexions o temperaments i la fisiognomonia (II), als aliments i els medicaments simples (III), a la higiene i el regiment de la sanitat (IV), a les malalties de la pell i la cosmètica (V), al regiment dels viatgers $(\mathrm{VI})$, a la cirurgia $(\mathrm{VII})$, als verins i les mossegades (VIII), a les malalties que afecten tot el cos (IX) i a les febres (X). Per a Rasís, la fisiognomonia té els seus principis teòrics en l'anatomia i en el tractament dels temperaments per després, amb els altres símptomes reorganitzats sobre la base de l'experiència clínica, orientar la pràctica del metge, amb la prescripció d'una dieta i una teràpia per a la conservació de la salut. En l'altra versió, pensada per a usos didàctics i professionals i que es difon amb el títol de Physionomia, la fisiognomonia circula independentment. La presentació clara i esquemàtica de la matèria, així com l'ordenació dels signes fisiognomònics des del cap fins als peus (a capite ad calcem) en van facilitar la consulta i l'ús (Agrimi 2002: 101-66). De l'èxit de l'obra en són testimoni les traduccions medievals a diverses llengües vulgars, com el francès, l'italià i el català (Cifuentes 2006: 93).

D'origen sirià i falsament atribuiit a Aristòtil, el Kitāb Sirr al-Asrār va ser traduït a l'àrab al segle $x$ i també conté una secció dedicada a la fisiognomonia (Grignaschi 1980, Ryan \& Schmitt 1982, Williams 2003). Com en el cas del llibre de Rasís, també d'aquest n'hi ha dues versions, que van arribar a l'Europa occidental llatina a partir del segle XII. La versió curta, que és la més antiga, està dividida en set o vuit llibres -segons els manuscrits- que constitueixen una mena de mirall de prínceps, basat en una suposada carta que Aristòtil va adreçar al seu deixeble Alexandre de Macedònia per a la seva instrucció durant 
la campanya de Pèrsia. La versió Ilarga, sorgida durant els segles XI i XII, va adquirir finalment un caràcter enciclopèdic ja que va afegir al primer nucli politicomoral i mèdic seccions més àmplies de medicina, filosofia i història naturals, astrologia, fisiognomonia, alquímia, numerologia i màgia.

La importància que tenen les fonts orientals en la disciplina la demostren unes paraules del viatger Marco Polo, que a finals del segle XIII va trobar fisionomistes a l'Índia Major, que correspon a l'actual Índia: «l us dic encara que entre ells hi ha molts savis en un art que s'anomena la Fisonomia, que ensenya a conèixer els homes i les dones, llurs qualitats i propietats, i si són bons o dolents: ho saben immediatament tot contemplant l'home o la dona» (Forcano 2009: 502).

\section{La fisiognomonia a la baixa Edat Mitjana}

La història de la fisiognomonia medieval és la història del procés d'homologació de la disciplina a la ciència escolàstica. En els primers decennis del segle XIII comença a l'Europa llatina occidental la reelaboració de la tradició fisiognomònica grega

Cap a la meitat del segle XII, Joan de Sevilla, que va treballar a Toledo, va traduir al llatí la versió curta del Kitāb Sirr al-Asrär, que s'ha conservat en uns cent cinquanta manuscrits. Un segle més tard, un enigmàtic Felip de Trípoli, del qual només sabem que va ser clergue a l'església llatina de Trípoli (de Síria) durant la primera meitat del XIII, va traduir la versió llarga al llatí amb un èxit espectacular, com ho proven els més de tres-cents cinquanta manuscrits que ens n'han pervingut. Testimoni de l'èxit del Secretum secretorum són les traduccions que se'n va fer a diverses llengües -a l'hebreu, turc, rus, txec, croat, alemany, anglès, castellà, català, portuguès, francès $i$ italià- $i$ els comentaris de què va ser objecte, entre els quals destaca el de Roger Bacon (Steele 1920). Sobre la tradició romànica del Secretum secretorum, amb especial atenció a tota la tradició manuscrita, vegeu Zamuner (2005), i per a les versions catalanes, Cifuentes (2006: 173-6i 430-3) i Zamuner (2006). i àrab, en uns ambients culturals (Ziegler 2001 i 2007) que, incitats pel descobriment i la introducció en els currículums universitaris de les obres de filosofia natural aristotèliques, es van interessar per la reconstrucció d'un saber científic i per l'elaboració d'una nova idea de natura.

Els filòsofs comencen a discutir l'estatut epistemològic -és a dir, quin és l'objecte d'estudi, els mètodes que utilitza, els principis en què es basa- de la fisiognomonia, que reclama un Iloc en l'ensenyament universitari. I l'aconsegueix gràcies a la tasca d'autors que la converteixen en una ciència perquè demostren que és una disciplina subordinada als principis de la ciència astronòmica, que procedeix racionalment. En aquest sentit, la recerca de les causes que produeixen els signes fisiognomònics, herència de la tradició filosòfica i natural aristotèlica, esdevé un moment decisiu per a la institucionalització de la fisiognomonia en la cultura universitària. La disciplina s'introdueix a la facultat d'arts de París entre els anys 1275 i 1286 i una mica més tard Pietro d'Abano la incorpora a l'ensenyament de les facultats de medicina del nord d'Itàlia, com Pàdua i Bolonya, atorgant-li una orientació medicoastrològica.

Aquest procés d'homologació culmina a començaments del segle XIV amb la redacció dels primers comentaris a la Physiognomonika pseudoaristotèlica, de Guillem de Mirica i de Guillem d'Aragó. El recorregut de la fisiognomonia medieval es clou amb l'Speculum phisionomie (1442) de Michele Savonarola.

A la difusió de la disciplina hi van contribuir també dues obres, en què la llengua vulgar té un pes important. La primera és un altre text pseudoaristòtèlic, conegut com a Problemata Aristotelis, que es va difondre en dues tradicions textuals, una amb un text més llarg que l'altra. De la versió llarga -els Problemata Aristotelis pròpiament ditsla traducció llatina sencera més antiga és la que va fer Bartolomeo da Messina entre el 1258 i el 1266 i que es va difondre per tot l'Occident llatí amb un comentari de Pietro d'Abano (1310). L'única llengua vulgar a la qual es va traduir el text va ser el francès, a finals del segle XIV (Guichard-Tesson 1989i 2006). La segona tradició textual, coneguda sobretot per l'íncipit Omnes homines, va ser 


\section{Obres fonamentals de l'homologació de la fisiognomonia com a ciència escolàstica:}

- El De physiognomonia liber d'un anònim llatí del segle Iv dC, ja esmentat, que presenta la fisiognomonia com a ciència i en reivindica l'especificitat enfront de la medicina i l'astronomia. El text va ser redescobert al segle XII i significa la represa de la tradició fisiognomònica antiga (Agrimi 2002:18-9).

- El segon tractat del Liber ad Almansorem de Rasís.

* El pseudoaristotèlic Secretum secretorum.

v El Liber phisonomie (1230) de Michael Scot, dedicat a l'emperador Frederic II Hohenstaufen, que segueix el model del Secretum secretorum i presenta un mestre que instrueix (Scot) i un deixeble que és instruït (Frederic), com Aristòtil i Alexandre. El llibre d'Scot, que classifica els caràcters i tipus d'individus partint dels signes del cos segons un sistema codificat de regles d'interpretació, significa la instauració definitiva de la fisiognomonia com a ciència, entesa com una scientia natural i moral alhora, que parteix del coneixement de les lleis biològiques que regulen la composició del cos humà. La fisiognomonia és «ingeniosa scientia naturæ per quam cognoscuntur virtus et vitium cuiuslibet animalis» (Jacquart1994, Agrimi 2002: 20-8).

v La Physiognomonika pseudoaristotèlica, que va ser traduïda al llatí per Bartolomeo da Messina i dedicada al rei Manfred de Sićlia (1258-1266). Es vincula així també amb la cort dels Hohenstaufen, protectora de les arts i de les ciències, i amb l'escola de medicina de Salern, que va tenir un paper molt rellevant en el procés del renaixement mèdic i natural que es va produir a l'Europa Ilatina occidental entre els segles XII i XIII (Agrimi 2002: 37-56).

t El Liber compilationis physionomie (1295) de Pietro d'Abano, que presenta una organització típicament escolàstica de la disciplina, definida com la ciència de les afeccions naturals de l'ànima i dels accidents del cos, que es modifiquen recíprocament, i les garanties de certesa de les quals s'han de buscar només en el coneixement de les seves causes universals i particulars. Pietro d'Abano traça la història de la disciplina, que té uns fundadors en el filòsof Aristòtil, el fisionomista Filemó i el metge i fisiognomonista Loxus, i unes auctoritates, com l'anònim llatí del De phisiognomonia liber, el Secretum secretorum i Rasís (Paschetto 1985, Agrimi 2002: 29-36). composta per un anònim llatí de final del segle XIII o començaments del XIV, segurament en l'àrea germànica, i va aconseguir una difusió notable, amb traduccions a l'alemany, al francès i a l'anglès. Escrits en forma de preguntes i respostes, els Problemata contenen diverses qüestions dedicades a la fisiognomonia. La segona obra és el Régime du corps d'Aldobrandino da Siena, de mitjan segle XIII, el primer regiment de sanitat escrit directament

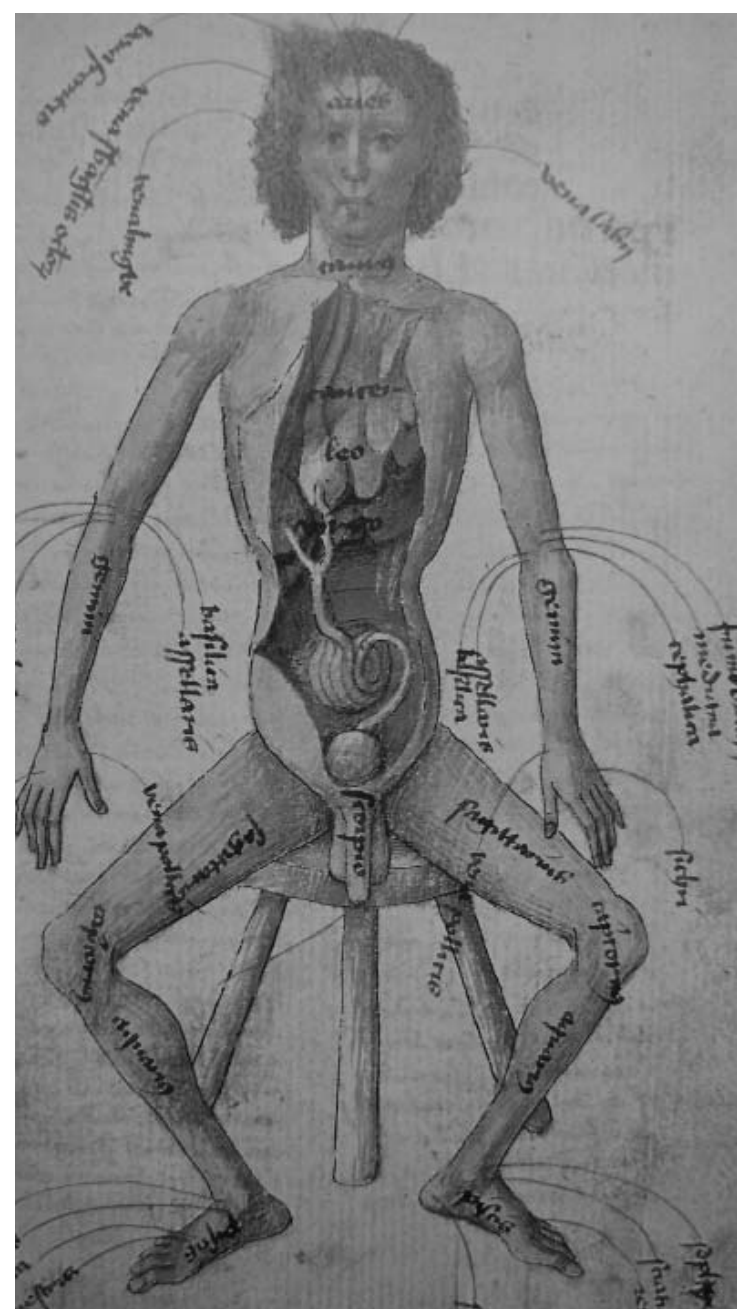

II.lustració anatòmica del ms. 18.2 Aug $4^{\circ}$ de la Biblioteca Herzog August (Wolfenbuttel, Alemanya).

en una llengua vernacla i que va aconseguir un èxit notable, com ho demostren la setantena de manuscrits francesos i les traduccions més o menys completes a l'italià, al català, al flamenc i al llatí. Conté un apartat de fisiognomonia que parteix de Rasís (Fery-Hue 1987, 1999i 2004). 
Si ens fixem en el vessant pràctic de la disciplina, a l'Europa medieval la fisiognomonia va ser conreada, sobretot, per metges que solien ser a més astròlegs i quiromàntics i que de vegades adquirien fama de mags, com Michael Scot o Girolamo Manfredi, que va assolir un gran èxit com a astròleg i de qui parlarem tot seguit.

\section{La vernacularització del saber fisiognomònic}

Amb l'ús de les llengües vulgars, la fisiognomonia salta les parets de les aules universitàries i arriba a un altre sector de públic, molt més ampli. La vernacularització del saber és un fenomen ben conegut: a partir del segle XIII i de costat amb el llatí, a l'Europa occidental les llengües vulgars esdevenen un mitjà de transmissió d'idees i cultura que arriben així a amplis sectors socials. L'expansió econòmica i demogràfica, els canvis socials, l'auge de les ciutats, l'impuls de les activitats comercials, el paper cada vegada més rellevant que prenia la burgesia, l'aparició dels ordes mendicants, van ser factors que van incidir en l'ús cada vegada més gran de les llengües vernacles com a instruments de comunicació i de difusió del saber entre nous sectors socials que ara accedien al món de la lectura i l'escriptura, en altre temps patrimoni quasi exclusiu dels clergues. De costat amb la reialesa i amb una noblesa cada vegada més urbanitzada, els membres d'aquesta nova burgesia - des dels rics mercaders fins als artesans més humils- es van interessar pels llibres que podien proporcionarlos els coneixements que les elits cultes adquirien a les universitats $\mathrm{i}$ que tenien utilitat en la seva vida quotidiana, tant per la seva aplicació pràctica com per la possibilitat que els oferien d'ostentar un saber socialment cada vegada més valorat.

Les obres de fisiognomonia també participen en tot aquest procés de difusió del saber científic i tècnic. Per centrar-nos només en el cas de la llengua catalana, fins ara hem vist que van circular traduccions catalanes del Secretum secretorum, del Liber ad Almansorem de Rasís i del Régime du corps d'Aldobrandino da Siena. Pel que fa al Secretum secretorum, una de les obres més llegides i influents de l'Edat Mitjana, se'ns han conservat traduccions catalanes de les dues versions, la curta i la llarga (Cifuentes 2006: 173-6 i 430-33 i Zamuner 2006). La curta, la més antiga que tenim, és inclosa parcialment en el Llibre de doctrina del rei En Jaume (Solà-Solé 1977, Garrido 2009, amb la grafia modernitzada), una collecció d'extractes de textos filosòfics pensada per a l'educació dels infants reials i elaborada possiblement durant el regnat de Jaume II a Sicília que conté un tractat «de les faiçons dels homes» (Kasten 1957: 89-91). La versió llarga es va traslladar al català durant el regnat del mateix Jaume II, i conté un tractat encara més extens «de la art de conèxer la qualitat dels hòmens», amb la seva aplicació pràctica en l'elecció de batlles, consellers, missatgers i altres oficials reials. La traducció catalana del Liber ad Almasorem de Rasís només ens ha arribat de manera fragmentària, en un manuscrit de mitjan segle XIV, però sabem que el text va circular sencer (Cifuentes 2006: 93). Del regiment de sanitat d'Aldobrandino da Siena se'n conserven dues traduccions catalanes diferents, datables a la segona meitat del segle XIV, i cap de les quals no inclou l'obra completa, sinó únicament el tercer tractat, dedicat a les propietats mèdiques de diversos aliments i begudes, amb el títol de Tractat de les viandes i dels beures (Cifuentes 2006:103).

El tractat de fisiognomonia més complet que tenim en català és el contingut en un incunable de 1499 que va ser imprès a Barcelona per Pere Posa amb el títol de Quesits o perquens (Carré 2004). Es tracta de la traducció catalana del Liber de homine o Il perché (1474) del metge bolonyès Girolamo Manfredi, un best-seller de l'època que va ser imprès en italià més de vint-i-cinc vegades al llarg dels segles XV, XVI i XVII, traduït al català el 1499 $i$ al castellà el 1567 (traducció reimpresa quatre cops més en un període de trenta anys, editada a Carré 2009). Escrit en forma de preguntes i respostes, seguint la tradició dels Problemata pseudoaristotèlics, aquesta obra de divulgació mèdica inclou un regiment de sanitat $i$ un tractat de fisiognomonia. Aquest darrer conté 240 preguntes, dividides en tretze capítols, que plan- 


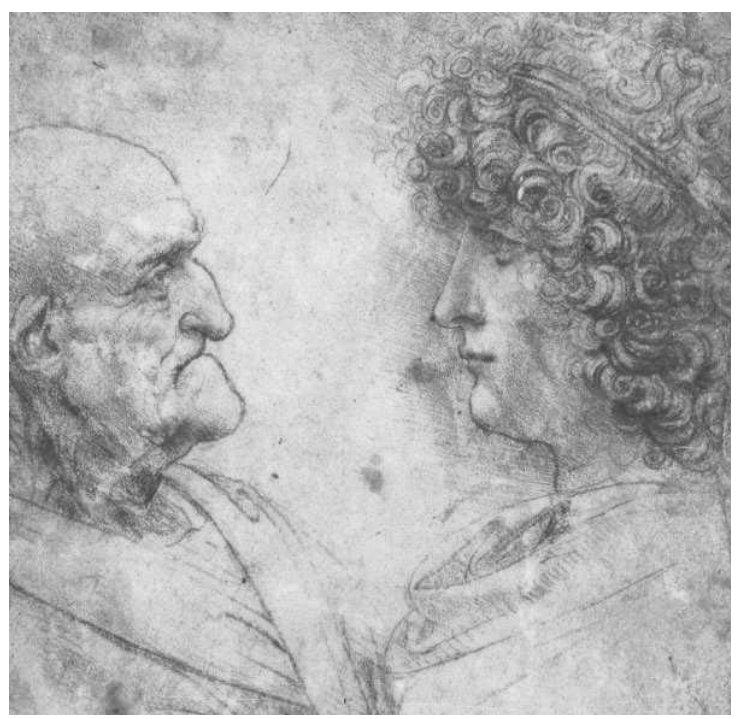

Leonardo da Vinci (1452-1519) es va interessar per la fisiognomonia i sabem que va llegir II perché de Girolamo Manfredi.

tegen qüestions relacionades amb els pèls i els cabells(I), el cap (II), els ulls (III), la boca (IV), les orelles $(\mathrm{V})$, el nas $(\mathrm{VI})$, les mans i els braços $(\mathrm{VII})$, els peus ( $\mathrm{VIII})$, el coll i l'esquena (IX), la veu i la parla $(X)$, els òrgans interns $(X \mathrm{I})$, l'estómac, la set i la gana (XII) i els membres de la generació (XIII).

A més, un còdex manuscrit del segle $X V$ del monestir de Ripoll, cremat amb gran part de la biblioteca el 1835, sabem que contenia un tractat de fisiognomonia en català, que malauradament mai no podrem identificar (Cifuentes 2006: 221-2). Finalment, com que la fisiognomonia està estretament vinculada amb l'astrologia, alguns tractats d'aquesta última disciplina també contenen capítols fisiognomònics, per exemple el recull miscellani que se'ns ha conservat en un manuscrit copiat a principis del XV i que ha estat batejat Astrologia de Vic, que té un apartat que tracta «de les semblances de fisolomia»(Cifuentes 2006:215i222). El terme utilitzat aquí, «fisolomia», revela que en aquest tipus de textos, més pràctics que teòrics, la visió de la disciplina que hi preval és la més acostada a l'experimentum i no pas la més filosòfica. Queden lluny els debats doctrinals de la universitat escolàstica: el públic nou i urbà que s'interessa per adquirir saber científic en una llengua vulgar se sent motivat sobretot per la seva utilitat pràctica. Per això un text com el Secretum secretorum -i a un altre nivell, Il perché de Girolamo Manfredi-té tant d'èxit, perquè parla dels signes del cos humà, però sense desenvolupaments teòrics, de manera que garanteix la memorització i l'exacta aplicació de les regles fisiognomòniques.

\section{La utilitat de la fisiognomonia}

El Secretum secretorum conté una anècdota sobre el fisionomista Filemó molt semblant a la que explicava Ciceró de Sòcrates. L'anècdota demostra que la fisiognomonia -i les «semblances de la fisolomia»- ha esdevingut un instrument indispensable de coneixement, però també de control. Les característiques físiques de l'individu en condicionen les tendències i les passions, però una fèrria voluntat pot modificar unes qualitats innates desfavorables. La ciència permet el domini de les pròpies inclinacions i serveix també per al bé comú, de manera que es proposa com un 'mirall' laic de vicis i virtuts (Agrimi 2002: 100).

A la baixa Edat Mitjana, la fisiognomonia servia, doncs, per analitzar la naturalesa humana i les seves inclinacions, però també per activar les oportunes estratègies educatives i per exercir

\section{Anècdota de Filemó}

Un dia, els deixebles d'Hipòcrates van dibuixar la cara del mestre i la van ensenyar a Filemó perquè n'interpretés els trets, d'acord amb les qualitats i les complexions. Filemó es va mirar el dibuix i va dir: «Vet aquí un home luxuriós, que es complau a practicar el coit.» Els estudiants, indignats, van voler matar el fisionomista i el van insultar a crits. «Estúpid, aquest és el rostre d'un dels millors homes del món!» Filemó els va respondre: «Aquest és el rostre del savi Hipòcrates. Però vosaltres m'heu demanat que me'l mirés segons la meva ciència, i això és el que us he contestat.» Aleshores els estudiants van anar a casa d'Hipòcrates i li ho van explicar tot. Hipòcrates els va contestar que certament, el que deia Filemó era veritat, però que ell (Hipòcrates), havent reconegut que aquestes coses eren pecaminoses, s'havia esforçat per convertir la seva ànima en la reina dels seus desitjos i que hi havia reeixit. (Tradueixo i resumeixo d'Agrimi 2002: 116.) 
un control social sobre els individus. En el seu comentari a la Physiognomonika pseudoaristotèlica, Guillem de Mirica diu que saber reconèixer la diversitat dels cossos humans i dels costums és necessari i útil per a la convivència social i per a l'individu, ja que permet evitar el contacte amb els malvats i serveix per escollir els homes bons (Agrimi 2002: 71-2), la mateixa aplicació pràctica que hem vist abans en el Secretum secretorum.

Atès que el saber fisiognomònic es podia utilitzar per identificar i corregir comportaments poc virtuosos, a partir del segle XIII les tipologies fisiognomòniques seran utilitzades per predicadors i moralistes en els seus discursos o sermons i esdevindran el centre d'interès d'un públic ampli, de cultura mitjana, que es convertirà en el potencial consumidor d'aquest tipus de textos. Estudiants i mestres d'arts, metges i astròlegs, reis i prínceps, consellers, nobles i burgesos, teòlegs i predicadors, i fins i tot aquells que han d'escollir esposes, criats o dides, buscaran informació en els textos fisiognomònics per no errar

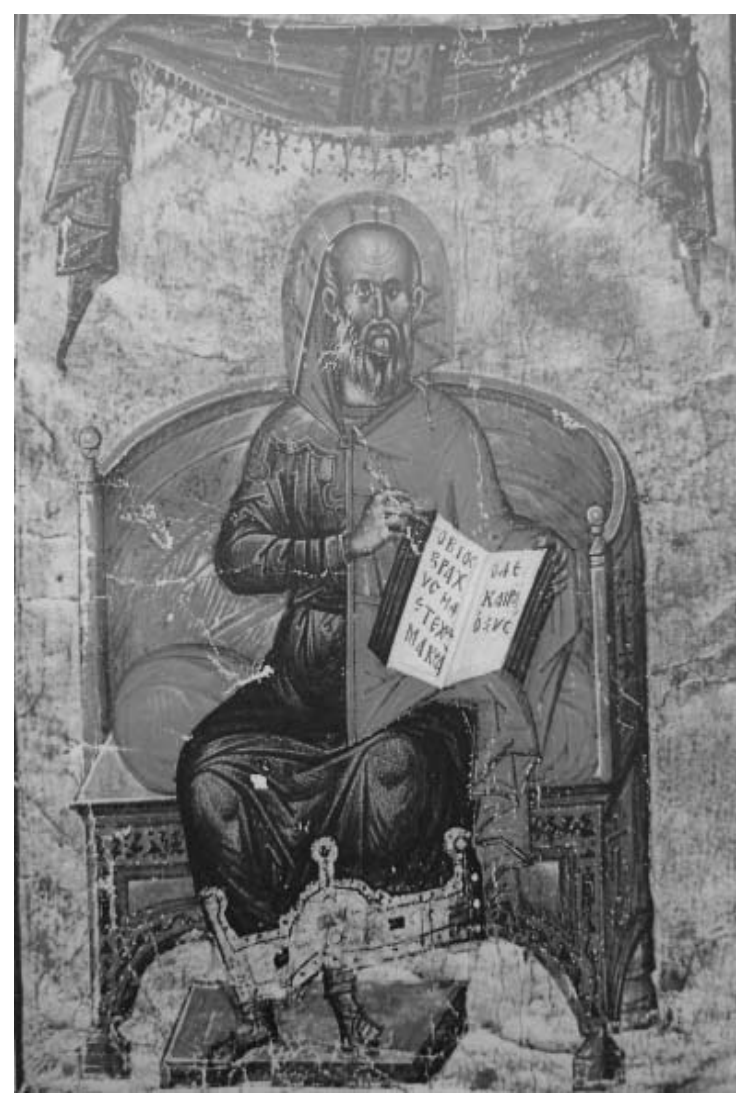

Hipòcrates representat en una miniatura bizantina del segle XIV la tria (Agrimi 2002:102). I així, la fisiognomonia penetrarà en els textos literaris, ja siguin obra de moralistes, de cronistes o de novellistes.

La difusió del Secretum secretorum, per exemple, era tan gran que en el capítol 564 del Dotzè del Crestià Eiximenis reporta una variant de l'anècdota de Filemó i Hipòcrates que diu que prové d'una font oriental. Eleucanus, rei de Panfília, que va conquerir tot Orient, era un home molt cast. «E diu la istòria oriental que un gran seu familiar dix-li una vegada: - Axí prech-vos, senyor, que digats, com podets viure tan castament? Respòs ell: —Dic-te que de ma condició yo són hom fort luxuriós, mas pensant lo mal que luxúria fa al gran hom, propose de treballar per obtenir castedat, e ab poch treball veig que.s pot optenir per aquell qui ardentment la vol.» (Wittlin 1986-87: I, 219-20).

\section{La fisiognomonia en els textos catalans}

Francesc Eiximenis podia haver llegit qualsevol dels textos de fisiognomonia que van circular a partir del segle XIII perquè com a bon teòleg hi tenia accés gràcies als seus coneixements de llatí. Hi podia haver accedit també de manera indirecta, a través de textos enciclopèdics.

El menoret s'havia proposat parlar àmpliament de temes fisiognomònics en el vuitè llibre del Crestià, però com que no ha arribat fins a nosaltres, ens haurem de conformar amb molt menys. Prendré en consideració només dos capítols del Dotzè, el 812 i el 813, que porten per títol, respectivament, «Com per fisonomia se pot l'om conèxer per via de natura» $i$ «Per quins senyals naturals pot hom conèxer naturalment a l'altre» (Wittlin 1986-87: II, 313-6).

En el capítol 812 exposa quines són les tres regles generals que regeixen la disciplina. En primer lloc, l'observació de l'ull, que ha de mantenir-se immòbil i tenir «algunes gotes negres», ja que la presència d'altres colors i la mobilitat excessiva indica que l'home té tendència a «aver males inclinacions». La segona regla és que «los menbres 
bé situats en lo cors de l'hom quant a la quantitat e al siti e al moviment e a la calor e a la figura, e en natural proporció e corespondència, donen gran senyal de bonea e aptea de la perssona en què són.» És a dir, un cos ben proporcionat $i$ harmònic, sense defectes, mostra una persona virtuosa. La tercera regla «general és aquesta: les persones qui han semblança en si matex d'alscuns animals, les costumes d'aquells retenen», amb la qual cosa segueix el mètode zoològic dels fisiognomonistes grecs, abandonat pels científics medievals que havien teoritzat sobre la matèria (Michael Scot, Pietro d'Abano), però mantingut viu pels textos de caire divulgador, com el de Manfredi. Si els autors de perfil més filosòfic havien renunciat a l'endevinació en benefici del caràcter científic de la disciplina, Eiximenis no cal que ho faci perquè es mou en un nivell més pràctic. Eiximenis segueix l'ordre expositiu dels tractats fisiognomònics i es refereix als senyals que es poden deduir del cap, el front, les celles, les orelles, el nas, la boca i la barba:

E per tal, aver lo cap massa gran, axí com ha l'ase, natural senyal han de aver poc seny; e que l'an agut, axí com l'esquirol, no són sinó tirivella e tots mobles, e van-ne ab lo cap alt, car no.ls pesa gens; no y ha cervell sinó fort poch, axí com en l'esquirol. E qui ha lo front estret axí com lo bugiot, tot és maliciós com lo dit animal. E qui ha les celles molt peloses e molt esteses envers los polsos, axí com han les bèsties, comunament à ferea bestial, car aver-les beles e bé archades - no per art, axí com les dones pintades, mas per natura- si s'ajunyen ab la pel del nas donen senyal d'om suptil e agut en sos afers. Aver, axí matex, grans orelles és senyal de poch seny axí com les bèsties, e aver-les massa petites és senyal d'om maliciós. Nas ben feyt dóna senyal de aptea de pensa, e si és massa gros ensenya que l'hom à terribles cogitacions e ferals; si és fonyat alt dóna senyal d'om maliciós e fembril. Gran boca és senyal d'om presumptuós e entrecuydat e de gran vorador; aver labis grossos és senyal d'om pagesívol e descurat. Barba roja ab fas de guineu significa l'om ab pocca pietat, tot maliciós, odiós e fals. Veu clara ensenyen l'om ab pocca fermetat e ab poca lealtat, mas és de longua vida e prea massa si mateix. Veu escura, axí com llop, significa hom cruel e vorant e maliciós; veu asinal e grossera significa hom grosser e pereós. (Wittlin 1986-87: II, 313-14)
Eiximenis té en compte també els senyals emesos per la veu de l'individu, com recomanava de fer Bartolomeo della Rocca Coclès en el seu tractat. I de la mateixa manera que Coclès aconsellava observar els moviments generals del cos, Eiximenis valora la gestualitat «car, per savi que l'om sia, si dolent és a la longa darà a conèxer defora per sos gests e per sos desigs e per ses maneres ell qui és, e quines inclinacions ha, car Déu ho vol e natura los hy tira», com diu en el capítol 813 (Wittlin 1986-87: II, 316).

El segon exemple és el famós retrat de Jaume I que fa Bernat Desclot en el capítol 12 del Llibre del rei En Pere. El passatge ha estat interpretat de diferents maneres, s'ha considerat com un tòpic literari i se n'han identificat les possibles fonts (Soldevila 2008: 68, n. 140), però pot ser llegit també en clau fisiognomònica:

Aquest rei En Jacme d'Aragó fo lo pus bell hom del món; que ell era major que altre hom un palm e era molt bé format e complit de tots sos membres, que ell havia molt gran cara e vermella e flamenca [=del color de la flama], e el nas llong e ben dret, e gran boca e ben feita, e grans dents belles e blanques que semblaven perles, e els ulls vairs, e bells cabells rossos semblants de fil d'aur, e grans espatlles, ellong cors e delgat, e els braces grossos e ben feits, e belles mans, e llongs dits, e les cuixes grosses, e les cames llongues e dretes e grosses per llur mesura, e els peus llongs e ben feits e gint causants [=que feien lluir el calçat]. E fo molt ardit e prous de ses armes, e forts e valent e llarg de donar, e agradable a tota gent e molt misericordiós; e hac tot son cor e tota sa volentat de guerrejar ab sarraïns. (Soldevila 2008: 68)

Primer de tot, l'aspecte general ben proporcionat $\mathrm{i}$ bell (aquest és l'adjectiu que hi apareix més vegades) és un senyal evident d'home de complexió temperada i, per tant, bo i virtuós, com també sap Eiximenis. La descripció de tots aquells òrgans susceptibles d'interpretació fisiognomònica confirma la bona constitució, física i moral, del personatge. La cara del rei és ampla i vermella, signes positius tots dos perquè el cap i la cara petits indiquen malícia de costums i el color vermell del rostre significa que l'home és alegre i benigne (Carré 2004: 251-6). El pitjor dels 
ulls és que es moguin en excés, com diu Eiximenis en el capítol 812, cosa que no fan els del rei Jaume, que són vairs, de color divers, difícil de concretar. Tampoc no els té vermells, que és el signe que identifica el tirà, com diu Pietro d'Abano (Agrimi 2002: 34). «Tal granesa de rojor de ulls significa l'ome ésser coleríssim e de grandíssima calor, de la qual natura proceexen pèssims costums e obstinacions» (Carré 2004: 206). La boca gran és un signe de menjar molt, però també d'audàcia (Carré2004: 213), qualitat que Desclot destaca al final del retrat. Les dents tenen origen en el cervell i en la matèria espermàtica, que es converteix en l'humit radical, la substància que vitalitza el cos i el manté en vida (Carré 2004: 214). Les dents grans i fortes, com les que té Jaume I, indiquen gran quantitat d'humit radical per tot el cos, doncs. Les espatlles grans són signe de bon intellecte perquè s'engendren i procedeixen de la virtut del cervell (Carré 2004: 233). A primer cop d'ull, l'aspecte físic del Conqueridor ja és definitiu.

Per acabar, ens fixarem en un altre personatge d'estirp reial, provinent d'una obra de ficció que no n'aporta cap descripció detallada, però el caràcter del qual pot ser interpretat gràcies a la ciència fisiognomònica. Es tracta de Felip, el fill del rei de França que a la novella de Joanot Martorell acompanya Tirant en el seu viatge a Sicília i a Rodes i que acaba casant-se amb la princesa Ricomana, I'hereva del tron de l'illa, gràcies a les intervencions providencials de Tirant, que aconsegueix de dissimular sempre la beneiteria del delfí.

Felip ha de ser físicament ben fet. Almenys això és el que indica Tirant a Ricomana en el capítol 110 de la novella, en un paràgraf que remarca la proporció de la cara, de les mans, dels peus i de tot el cos del pretendent. També n'assenyala les virtuts eròtiques, ja que Tirant afirma que si Ricomana tingués Felip al llit no en quedaria malcontenta. Pel que fa a les virtuts morals, Tirant assegura que Felip és valent, generós i més savi que no pas grosser, virtuts que, pels fets que se'ns van explicant, qui llegeix el Tirant lo Blanc sap que Felip no posseeix. Tirant, doncs, aquí menteix i ho fa a posta:
La celsitud de vostra excellència, senyora de totes virtuts complida, me fa estar admirat, per ésser vós la més discreta donzella que jo jamés haja conegut, que vol l'altesa vostra fer procés de pensa a Felip, lo qual (salvant la honor de l'excellència vostra) no proceeix de justícia ni menys de caritat, per ço com Felip és hui u dels bells cavallers del món: jove, dispost més que tot altre, animós, lliberal e més sabut que no grosser, e per tal és ell tengut en totes les parts on som anats, de cavallers, dones e donzelles. E fins a les mores que el veien l'amaven e el desijaven servir. Si no, mirau-li la cara, los peus e les mans e tot lo cos. E si tot nuu lo voleu veure, jo m'hi sent bastant de fer-ho, senyora, que entre la bellesa e castedat ha gran contrast. Jo sé que vostra altesa l'ama en extrem grau, e cert tal és ell que es fa amar a totes gents. E culpa gran és de vostra senyoria com no el teniu al costat en un llit ben perfumat de benjuí, algàlia, almesc fi, e a l'endemà si vós mén dieu mal, jo vull passar la pena que l'altesa vostra voldrà. (Riquer 1979:346)

Qui l'encerta del tot és el filòsof de Calàbria, que Ricomana fa venir perquè li desvetlli quina és la veritable naturalesa del seu enamorat. El filòsof

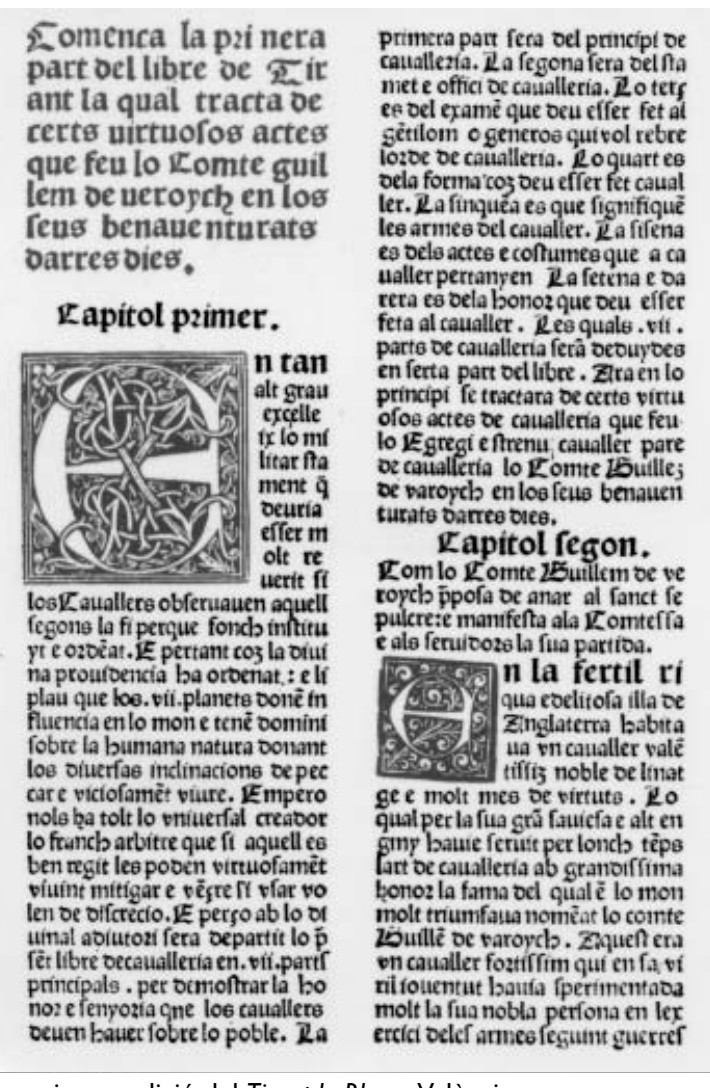

La primera edició del Tirant lo Blanc, València 1490. 
confirma la bellesa física de Felip -la qual cosa ens indica que Tirant no mentia en aquest punt-, però també la seva estupidesa i avarícia. I ho fa usant les regles de la fisiognomonia:

Senyora, lo galant que la senyoria vostra m'ha fet veure porta l'escrit en lo front de molt ignorant home e avar. E dar-vos ha a sentir moltes congoixes. Serà home animós e valentíssim de sa persona e molt venturós en armes e morrà rei. (Riquer 1979:352)

El front de Felip ha de ser bàsicament gran, perquè el front gran significa que l'home s'inclina a l'estultícia, mentre que el front petit significa bondat d'enteniment. Així ho diu Girolamo Manfredi:

«Per què quant lo front de l'home és gran significa l'ome declinar a stultícia, e lo front petit significa bondat de enteniment?» Lo front és un os molt gros, on per la sua grossea no pot penetrar ni bé evaporar la fumositat del cap per aquell loch. E per ço, quant l'os del front és major, tant més prohibex que les parts anteriors del cervell no:s mundifican de les fumositats que múntan, perquè ocúpan molta part de la comissura davant; on, a tal home li vola lo cervell per turbulència que reb lo spirit d'aquelles parts de les dites fumositats. E per aquesta raó, l'ome qui ha lo front molt carnós és de judici no molt bo, per quant no pot líberament respirar fora los fums de aquella part. E encara, en lo front qui és gran los spirits no stan reposats, havent gran loch, ans se mouen ara de una part ara d'altra, de què tals hòmens són de molta fantasia e sovint se múdan de opinió e propòsit. E, per lo contrari, qui ha lo front petit, poch carnós, ha més stabilitat e fermesa de judici, car poden-se millor mundificar les fumositats de les parts davant. E, encara, en lo front petit stan més reposats los spirits, no movent-se axí com fan allà, on ha gran distància de loc a loc, com és en los grans fronts. (Carré 2004:195)
El front de Felip devia ser tan ample i evident, que el filòsof de Calàbria no necessita ni analitzar-li els ulls per fer-se una idea del personatge. Segurament, els devia tenir sortits enfora, signe que en corroboraria l'estultícia i que li afegiria les dues altres característiques que el filòsof i Tirant remarquen del seu caràcter: l'avarícia i el bon fer al llit:

«Per què l'ome qui ha l'ull petit fora eminent, com són los ulls del gàmbero, és senyal d'estultícia, e que tal home és avar e seguidor de tots los seus desigs e cupiditats?») La stultícia proceex de debilitat de intellect[e], e la debilitat de intellecte proceex de mancament de cervell. E per quant los ulls petits significan poquesa de matèria, de la qual són engendrats, de què havent orígine del cervell significa mancament de aquell. E, d'altra part, l'ull qui és fora eminent tost comprèn moltes coses, on no pot de tantes coses axí tost judicar, ans sens delliberació ha lo seu judici e, consegüentment, no és de bon intellecte. Quant, donchs, se conjunyen aquestes dues coses ensemps, ço és poquesa de ulls e eminència defora, fan l'ome ultra mesura leuger de intellecte. E per quant la avarícia e cupiditat no proceex sinó d'estultícia, e de no poder conèxer lo dret de l'envers e, semblantment, lo seguir de les sues cupiditats e desigs proceex de poquesa de intellecte, per ço tals hòmens qui han los ulls petits e fora eminents han la condició sobredita. (Carré 2004: 207)

Al final de l'episodi, i consumat el matrimoni de Felip i Ricomana, la princesa mateixa s'encarrega de confirmar la predicció de futur que li havia fet Tirant: «ella restà molt contenta de Tirant e molt més de Felip, que li féu tal obra que jamés l'oblidà» (Riquer 1979: 357). 


\section{Bibliografia}

Agrimi, Jole, 2002: Ingeniosa Scientia Nature. Studi sulla fisiognomica medievale, Florència: SISMELGalluzzo.

BOUDET, Jean-Patrice, 2006: Entre science et nigromance: astrologie, divination et magie dans l'Occident médiéval ( $X \|^{e}-X V^{e}$ siècle), París: Publications de la Sorbonne.

Burnett, Charles, 1996: Magic and Divination in the Middle Ages: Texts and Techniques in the Islamic and Christian Worlds, Aldershot: Ashgate Variorum.

Caro Baroja, Julio, 1988: Historia de la Fisiognómica. El rostro y el carácter, Madrid: Istmo.

Caro Baroja, Julio, 1995: La cara, espejo del alma: historia de la fisiognómica, Barcelona: Galaxia Gutenberg.

Carré, Antònia (ed.), 2004: Girolamo Manfredi, Quesits o perquens (regiment de sanitat i tractat de fisiognomonia), Barcelona: Barcino.

CARrÉ, Antònia (ed.), 2009: Girolamo Manfredi, Libro llamado el porqué. Régimen de salud y tratado de fisiognomonía. Traducción castellana de Pedro de Ribas (1567), San Millán de la Cogolla: CiLengua.

Cifuentes, Lluís, 2006: La ciència en català a l'Edat Mitjana i el Renaixement (2002), BarcelonaPalma: Univ. de Barcelona-Univ. de les IIles Balears; $2^{\text {a }}$ ed. revisada i ampliada.

Corman, Louis, 1966: Nouveau Manuel de Morpho-Psycologie, París: Stock.

CouIssin, J, 1953: «Suétone physiognomoniste dans les Vies des XII Césarsı, Revue des Études Latines, 31, 234-256.

Evans, E. C., 1969: Physiognomics in the Ancient World, Philadelphia: American Philosophical Society.
Federici Vescovini, Graziella, 1996: «L'individuale' nella medicina tra medioevo e umanesimo: la fisiognomica di Michele Savonarola», Umanesimo e medicina: Il problema dell'«individuale», ed. R. Cardini i M. Rogoliosi, Roma: Bulzoni, 63-87

Fery-Hue, Françoise, 1987: «Le Régime du corps d'Aldebrandin de Sienne: tradition manuscrite et diffusion», Actes du $110^{e}$ Congrès National des Sociétés Savantes: Section d'histoire médiévale et de philologie, París: CTHS, I, 113-4.

FerY-Hue, Françoise, 1999: «Le Régime du corps d'Aldebrandin de Sienne: complément à la tradition manuscrite», Romania, 117, 51-77.

FERY-HuE, Françoise, 2004: «Le Régime du corps d'Aldebrandin de Sienne: complément à la tradition manuscrite (suite)», Scriptorium, 58.1, 99-108.

Forcano, Manuel (trad.), 2009: Marco Polo, La descripció del món. Llibre de les meravelles, Barcelona: Proa.

FöRSTER, Richard, 1893: Scriptores physiognomonici græci et latini. Recensuit Richardus Fœrster, Leipzig: Teubner, 2 vols.

GABARRE, Julián, 2001 (2000): El rostro y la personalidad: inteligencia, carácter y aptitudes, Barcelona: Flumen.

García Ballester, Luis, 1972: Alma y enfermedad en la obra de Galeno. Traducción y comentario del escrito "Quod animi mores corporis temperamenta sequantur», ValènciaGranada: Univ. de Granada.

García BALleSter, Luis, 2001: La búsqueda de la salud: sanadores y enfermos en la España medieval, Barcelona: Península.

GARRIDO, Josep-David (ed.), 2009: Jaume I, Llibre de saviesa (Llibre de doctrina), València: Tres i Quatre.
GRIGNASCHI, Mario, 1980: «La diffusion du Secretum Secretorum (Sirr alAsrār) dans l'Europe occidental»», Archives d'historie doctrinale et littéraire du Moyen Âge, 55, 7-70.

GUICHARD-TESSON, Françoise, 1989: «Le métier de traducteur et de commentateur au XIV viècle d'après Évrart de Conty»», Le Moyen Français, 24-5, 131-67.

GUICHARD-Tesson, Françoise, 2006: «Évrart de Conty, poète, traducteur et commentateur», Aristotle's Problemata in Different Times and Tongues, ed. P. de Leemans i M. Goyens, Lovaina: Leuven UP, 145-74.

JACQUART, Danielle, 1994: «La physiognomonie à l'époque de Frédéric II: le traité de Michel Scot», Micrologus: Natura, Scienze e Società Medievali, 2 [=Le scienze alla corte di Federico II / Sciences at the Court of Frederick II, ed. V. Pasque], 19-37.

JACQUART, Danielle i Françoise MicheaU, 1996: La médicine arabe et l'Occident médiéval, París: Editions Maisonneuve et Larose.

Kasten, Lloyd A. (ed.), 1957: Pseudo Aristóteles, Poridat de las poridades, Madrid: Seminario de estudios medievales españoles de la Univ. de Wisconsin.

LouIs, Pierre (ed.), 1991-94: Aristote, Problèmes, París: Les Belles Lettres, 3 vols.

Martínez Manzano, Teresa i Carmen Calvo Delcán (trad.), 1999: Pseudo Aristóteles, Fisiognomía. Anónimo, Fisiólogo, Madrid: Gredos.

MonfasANI, John, 1999: «The PseudoAristotelian Problemata and Aristotle's De Animalibus in the Renaissance», Natural particulars: Nature and the disciplines in Renaissance Europe, ed. A. Grafton i N. G. Siraisi, Cambridge: MTI Press, 205-47. 
PAschetto, Eugenia, 1985: «La fisiognomica nell'enciclopedia delle scienze di Pietro d'Abano», Medioevo, 11 [=Pietro d'Abano], 97-112.

PORTER, Martin, 2005: Windows of the Soul. Physiognomy in European Culture 1470-1780, Oxford: Clarendon Press.

Rapisarda, Stefano i Rosa Maria Piccione (eds.), 2005: Manuali medievali di chiromanzia, Roma: Carocci.

RiBA, Carles (trad.), 1942: Plutarc, Vides paralleles. Alexandre i Cèsar, Barcelona: Fundació Bernat Metge.

Riquer, Martí de (ed.), 1979: Joanot Martorell, Tirant lo Blanc (1969), Barcelona: Ariel.

Ryan, W. F. i Charles B. Schmitt (eds.), 1982: Pseudo-Aristotle the Secret of Secrets. Sources and Influences. Londres: The Warburg Institute.

SIRAIII, Nancy G., 1973: Arts and Sciences of Padua: The Studium of Padua before 1350, Toronto: Pontifical Institute of Mediæval Studies.

SolÀ-SolÉ, Josep M. (ed.), 1977: Jaume I d'Aragó, El llibre de doctrina, Barcelona: Hispam.

SOLDEVILA, Ferran (ed.), 2008: Les quatre grans cròniques. Vol. II Crònica de Bernat Desclot, rev. J. Bruguera i M. T. Ferrer i Mallol, Barcelona: Institut d'Estudis Catalans.
Steele, Robert (ed.), 1920: Opera hactenus inedita Rogeri Baconi, Fasc. $\mathrm{V}$ : Secretum secretorum cum glossis et notulis, Oxford: Clarendon Press.

VAL NAVAL, Paula, 2006: «Autoría y datación de la Summa supra phisonomiam Aristotelis», Studium. Revista de Humanidades, 12, 127-140.

VALENTí, Eduard (ed.), 1948-50: Ciceró, Tusculanes, Barcelona: Fundació Bernat Metge, 3 vols.

WiLLIAMs, Steven J., 2003: The Secret of Secrets: The Scholarly Career of a Pseudo-Aristotelian Text in the Latin Middle Ages, Ann Arbor: The Univ. of Michigan Press.

WITTLIN, Curt (ed.), 1986-87: Eiximenis, Dotzè del crestià (segona part), Girona: Collegi Univ. de GironaDiputació de Girona, 2 vols.

WURTELE, Douglas J., 1999: «Another look at an old 'science': Chaucer's pilgrims and physiognomy», From Arabye to Engelond: Medieval Studies in Honour of Mahmoud Manzalaoui on His $75^{\text {th }}$ Birthday, ed. A. E. C. Canitz i G. R. Wieland, Ottawa: Univ. of Ottawa Press, 93-111.

ZAMUNER, llaria, 2005: «La tradizione romanza del Secretum secretorum pseudo-aristotelico. Regesto delle versioni e dei manoscrittis, Studi Medievali, $3^{\mathrm{a}}$ sèrie, 46, 31-116.

ZAMUNER, llaria, 2006: «ll volgarizzamento catalano $\mathrm{Ctz}$ del
Secretum secretorum ps.-aristotelico e il codice 1474 della Biblioteca Nacional di Madrid», Quaderni di lingue e letterature [dell'Università di Verona], 31, 237-45.

ZIEGLER, Joseph, 2001: «Text and Context: On the Rise of Physiognomic Thougth in the Later Middle Ages», «De Sion exibit lex et verbum domini de Hierusalem». Essays on Medieval Law, Liturgy and Literature in Honour of Ammon Linder, ed. Y. Hen, Turnhout: Brepols, 159-82.

ZIEGLER, Joseph, 2004: «Médecine et physiognomonie du XIV au début du XVI siècle», Médiévales, 46, 89-108.

ZIEGLER, Joseph, 2007: «Philosophers and physicians on the scientific validity of Latin physiognomy, 12001500», Early Science and Medicine, 12.3, 285-312.

ZiEGLER, Joseph, 2008: «Hérédité et physiognomonie», L'hérédité entre Moyen Âge et Époque moderne: perspectives historiques, ed. M. Van der Lugt i C. de Miramon, Tavarnuzze: SISMEL-Edizioni del Galluzzo, 245-72.

ZIEGLER, Joseph, 2009: «Physiognomy, science, and proto-racism (12001500)», The Origins of Racism in the West, ed. M. Eliav-Feldon, B. Isaac i J. Ziegler, Cambridge: Cambridge UP, 181-99. 